\title{
The Basis for Beliefs in Luo Ancestral Spirits among the Seventh-day Adventists Church Members in the Kenya Lake Conference
}

\author{
Ogayo Luka Otieno *, Dr. Richard Ayako (DMin) ${ }^{* *}$, Dr. Daniel Rotich Kandagor, PhD ** \\ ${ }^{*}$ PhD Student, Department of Philosophy and Religious Studies, Kisii University \\ ${ }^{* *}$ Lecturer, School of Arts and Social Sciences, Kisii University \\ DOI: 10.29322/IJSRP.11.07.2021.p11527 \\ http://dx.doi.org/10.29322/IJSRP.11.07.2021.p11527
}

\begin{abstract}
The backdrop under which this study was undertaken was the persistence participation in community rituals pertaining to Luo ancestral spirits among Seventh-day Adventist Church members in the Kenya Lake Conference. This is evidenced during events such as the birth of a child, death of a family member, and in tragedies like sicknesses. Hence, some of the members who correspondingly had accepted the Gospel truth as taught by Seventh-day Adventist Church still continue to hold to aspects pertaining to Luo traditional worship. These possess a problem as to whether these members belong to the SDA Church or believe in Luo ancestral sprints. The present situation is a kind of dual allegiance demonstrated in worship among SDA Church members in Kenya Lake Conference. One of the objectives of the study was to examine the basis for beliefs in ancestral spirits among Luos in Kenya Lake Conference. The study adopted a descriptive research design as a suitable way for collecting information about people's attitudes, opinions, habits and views on social issues affecting a given population. It included interviews, observations, and openended questions in the questionnaire done through multi-method data collection approach. The findings were analyzed through MAXQDA 2020 and and Statistical Package for the Social Sciences (SPSS) Version 23.0 after which it was presented using tables, figures, chats and continuous prose form. The study was informed by two major theories namely: functional and essentials of religion as presented by Durkheim (1912) and Otto (1917) respectively. The study revealed that Seventh-day Adventist Church members in the Kenya Lake Conference continue to hold believe in ancestral spirits, which are associated with fear and bad omen. The study also indicated that the basis for belief in ancestral spirits is the practice of witchcraft, magic, ancestral spirits veneration, and prolonged illness ("Sote"or Midekre).
\end{abstract}

Index Terms- Ancestral spirits, bad omen, fear, beliefs, traditional, worship, practices, dual allegiance

\section{INTRODUCTION}

$\mathrm{T}_{\mathrm{t}}$ he Seventh-day Adventists message first arrived in Kenya Lake Conference in the year 1906, before spreading to other parts of the country. The inhabitants of the area embraced Seventh-day Adventist teachings even though amidst myriad challenges. Nevertheless, 17 (seventeen) people were immediately baptized and the number has continued to expand to the current membership of 90608 (ninety thousand six hundred and eight). Notwithstanding the fact that there is a marked numerical growth based on the figures indicated above, some of the members who correspondingly had accepted the Gospel truth as taught by Seventh-day Adventist Church still continue to hold to aspects pertaining to ancestral spirits, a situation that can be described as dual allegiance. This was the backdrop that led to a study to examine the basis for beliefs in ancestral spirits among Luos in Kenya Lake Conference. Therefore, this study examines different aspects pertaining to Luo beliefs in ancestral spirits in order to establish why the Luo Christians in the Kenya Lake Conference have continued to hold to the beliefs while embracing the Seventhday Adventist teachings.

\section{BASIS FOR BELIEFS IN ANCESTRAL SPIRITS}

Based on the understanding that beliefs in ancestral spirits are considered functional religious aspects alluded to by Barkan, S.E., and Greenwood, S. (2003), whose thoughts originate from functional theory of Durkheim (1912), its validity may require a thorough historical background. In this respect therefore, the concept of ancestral spirits as indicated by Wiginton (2019) has a long history dating back to the ancient cultures where members of society venerated those who came before them and the same trend is in continuance in the contemporary societies. Ancestral veneration goes hand in hand with respect due to older parents though dead is still regarded as the makers of the present communities and families. Hence, it is purely not strange to find celebrations that honor the ancestors in a variety of different ways. Some of the topics discussed in this section are veneration of the dead, the existential relevance for security, solidarity of the community, Sacrificial Offerings for Appeasement, and historicity of ancestors.

\subsection{Veneration of the Dead}

Veneration of the dead is a widespread phenomenon that has various implicating influences on people irrespective of time, place, race or specific background under the globe that ought not to be lightened. According to HISTORY OF CHINAANCESTOR WORSHIP, VENERATION AND OFFERING IN TAOISM (2017), belief in ancestral spirits is a religious practice 
based on the views that the spirits of the deceased ancestors will look after the survived family members, take an interest in the affairs of the world, and possess the ability to influence the future of the living. Moreover, ancestral spirits' veneration is an obligating pay back honor and respect to the makers of the current generation as stated in ANCESTOR WORSHIP, VENERATION AND OFFERING IN TAOISM (2016) that the ancestors are the ones having brought the descendants into the world, nourished them and having prepared the conditions under which the descendants grew up, deserve veneration from their descendants as a compensation of spiritual debts. Veneration of the dead is found among Mexican communities in the United States, who have set the Day of the Dead to be celebrated on November 1, in which families gather together, pack picnic lunches, and go to cemeteries to honor the memories of family members who have died in the past years (Wigington 2019). According to SAHO (2019), South Africans uphold beliefs in ancestral spirits as an extension of believe in and respect for elders maintaining that ancestors have continuous spiritual connections with their living relatives. The notion associated with this belief is that most ancestral spirits are generally good and kind. Nevertheless, SAHO (2019) continues to emphasize that negative actions taken by ancestral spirits may cause minor illnesses as warnings to people who might stray but the wrath of the spirits on such circumstances possibly could be appeased by offerings of foods in terms of beer and meet. The idea is supported by Mbiti (1969) who postulates that after the assumed physical death, the individual continues to exist in the Sasa period and not immediately disappear from it. In essence, such a person continues to exist both socially and spiritually in the minds of the survived family members and relatives for several decades as long as those who knew him cease to exist. Such a concept in African belief in ancestral spirits indicates that no one dies not only from the memory of the survived ones, but also assumes immortality. Similar sentiments are shared by Nurnberger, (2014), Kwasi (1998), and Gehman (2005) that physical life is not the end but a beginning of another life, and that the dead have contact with the living.

In the like manner, the basis for belief in ancestral spirits and the veneration of the dead relates to the submission by Bondi (2015) that if proper burial rites are not observed, the deceased may become a wandering ghost, unable to exist in a proper manner after their death and are thus become a menace to those whom they have left behind. Hence, proper death rites are more a guarantee of protection for the living than to secure a safe transitional phase for the dying. At the same time, Powell (2019) points out that cautions are taken during burials to protect the living from harsh ancestral spirits that are thought of to have caused death by appeasing the spirits through elaborate burial rites and customs of shutting the eyes of the deceased which appears to be in practice today. Proper burial assures the survived family members of both reconciliation and appeasement that provide authentic peace for posterity. The continuance and importance attached to families are pertinently regarded as key elements in biblical epochs as indicated in the book (1Chronicles 1-10). Hence, these submissions concerning death in connection with ancestral spirits as presented are geared to validate the reasons African believer in ancestral spirits finds it a necessity to embrace it for existence and continued security in the present life and the afterlife.

\subsection{The Existential Relevance for Security}

Another possible component that fosters beliefs in ancestral spirit is relating to existential relevance which Nurnberger (2014) explains in terms of approximate ancestors who belong to the domain of applied relationship between the currently alive and the living dead. Since the ancestors have been personal participants in the network of social relationships until very recently, they are known and are part of their families. Hence, through the sphere of existential relevance, one finds straight forward colorful solutions to their problems unlike the farfetched ancient biblical mythologies. It is on this strength that Hiebert (1999) sets out four essential elements in favor of existential relevance with the ancestors: (i) that ancestors being the founders of families, they have natural interests in caring for it, (ii) that ancestors who have experienced death are well positioned to address humans' questions of what follows after death, (iii) that ancestors are remembered for the great works they performed during their life time among the living, and (iv) that they are thought of having wellbeing of families at heart. These ideas suggest continual communication with ancestors for the good of the family or community involved. Addressing the same subject, Aladokan (2013) states that when approaching the spirits or ancestors, we must deal with them from an empowered, mature, clear, and strong position. This position requires that the descendants of the ancestors must exercise utmost sincerity and clarity in their presentation of their petitions in cognizance that the needs are unambiguously stated to ancestors in order that they may act upon them appropriately. Hence, every appeal to the ancestors must be presented with maximum sincerity and forthright honesty based on the knowledge that in case there are misperceptions, some malevolent spirits may stir more confusion to the peril of the family or community at large.

Similarly, Deborah (2016) asserts that there are instances for having a human spiritual experience with the dead as a therapeutic means to repulse pain of losing the loved ones at death. Such experiences come through dreams and to some extent, visions in which the dead appears in the physical form to the survived member(s) of the family. It seems therefore that connecting with the spiritual realms and knowing that life goes on, clear fears, doubts, and negative emotions are swept out of ones' consciousness by the light of love and spiritual connection with the dead. In other developments, the bereaved are assured with consoling statements that in Luo language states that: tho e ngas mi dhigo e Polo which is translated to mean (death is the ladder to heaven). In like manner, Nurnberger (2014) points out that it is perceived that the living and the deceased communicate with each other in some forms, including when the living expect support from ancestors or in case they fear punishments based on instances of waywardness. This may take a corporate dimension since matters of health and security of the Luo community are not circumscribed upon individual sufferer. It is on this light that Mndende (2005) mentions that feelings of health, sicknesses, and being healed involve not only individual member but also affects relationship between an individual and other members of the community including ancestors. The rationale in this is that spirits are pentagonal in the sense that they: see, hear, feel, understand, and communicate with the living and they may make moral judgments over daily happenings among the living. In addition, Mndende (2005) postulates that the spirits are wishful, willful, 
joyful, angry, stern, permissive, kind, cruel, and sometimes capricious based on clear connotation that they have all the positive and negative emotions and traits of human beings.

Based on the assumed fears surrounding humanity, EvansPritchard (1934) points out that many Africans are attracted to aetiologic -the philosophical study of causes of diseases. Thus, for the religion of any particular African people, the dominant motif is usually what people attribute to dangers and sickness and other misfortunes including possible that steps may be taken to avoid or eliminate such dangers at the existential levels. It is on this account that Gehman (2005) asserts that the Supreme Being is for many people relatively unimportant, since He is rarely conceived either as a cause of misfortune or as an important means of redress. The most important means is rather ancestors, witches, sorcerers, malevolent spirits and the like which tends to be the primary focus of African concern, because they are identified as the primary source of affliction and are at the same time able to thwart them.

Since humans are prone to illness and sufferings in various forms, matters of life-giving powers become crucial. Based on this assumption, Ring, Nash, MacDonald, Glennon \& Glancy (1998) assert that there is common understanding in various religious communities that humans are part of a powerful mystery of life. In this regard, there are incessant religious struggles with facts of illness, suffering and the means by which human needs may be met. Appealing to this view point, Richards (2016) explains six human needs that are in the context of: certainty, variety, significance, love and connection, growth and contribution as emotional virtues that are attached to human feelings and require fulfillment with either the Supreme Being or the ancestral spirits. However, the underlying remedy may only be realized through existential relevance that exists between the living and the ancestors.

The same idea is further discussed by Hiebert (1999), who upholds that the wellbeing of the community in terms of basic needs and other blessings depends upon the veneration of the ancestral spirits. The good ancestors are responsible for the provisions of rain and good harvest that are vital in solving humans' basic needs. However, in view of family relations and psychological healings, Hiebert (1999) states that family is a central theme in God's plans for the stability of human society. Therefore, it is of great importance to esteem the demands of every human family as intended from the beginning. In order to address these noble traits in the African context, Hiebert (1999) points out that adhesive human society will readily find its biological attachment with ancestral spirits in terms of fear and respect for therapeutic remedies to the community at large.

Nevertheless, it is also asserted by Merwe (2008) that veneration of ancestral spirits must be seen comprehensively as matters of social functions and ethical motivations essential to practices that cannot be isolated from the religious elements. Hence, veneration of ancestral spirits should suffer no blames on violation of divine principles but rather be treated as extensions of family responsibilities to their relatives whom they lived with before. It follows therefore, that such relationships are subject to foster help when need arises as Hiebert (1999) indicates that the affected individuals in the African context would choose to seek assistance from ancestors with whom they have blood relations other than seeking for supernatural Divine interventions. Furthermore, in discussing the relations that exists in the African mind, Nurnberger (2014) compares Christian obligation and African relevance by stating that:

Relevance is experienced as social authority and redemptive power. If Christ is not relevant in these two respects, one has to find one's way through life without Him. As the Ganda says, 'when the Leopard comes to you, the club at your neighbor's won't drive it off'... African spirituality is characterized by presence... Outer spheres of influence are less relevant than the more proximate ones.

It follows therefore from the submission of Nurnberger (2014) that where communicative gap exists between Christ and the community, it will be filled with more proximate powers, which are one's living and deceased superiors. Hence, any unearthly insight concerning salvation may not satisfy an African Christian believer who is craving for life in its fullness here and now. This shows that an African believer in existential relevance through ancestral spirits has to bring the two faceted options in worship together in order that he may experience the peace that he or she desires as pegged on human correlation. In essence, human relationship as observed by Wach (1944) becomes a bond with ties that stimulates spiritual wellbeing of the community and its solidarity.

\subsection{Solidarity of the community}

The idea advanced by Ogude (2017) in the expression of "umuntu ngumuntu ngabantu" meaning that, a person is a person through persons, enforces African dependability on other persons for existence. Hence, Ubuntu is the African idea of personhood in which persons depend on other persons to be. The Luo community thrives well in societal solidarity gleaned from sharing aspect known as "Cham gi wadu" which can be translated as "eat the little you may have with your neighbor" Thus, in an attempt to solve an African problem that confront individuals, the sense of leaning upon humans rather than God is a lasting reality among Africans. The same notion is alluded to by Mbiti (1970), who postulates that: "I am because we are, and since we are, therefore I am." This shows that personal identity of the African is rooted in the family, the clan, the tribe, and the community including ancestors. Thus, individualism distinguished in the West is rarely practiced in Africa.

\subsection{Sacrificial Offerings for Appeasement}

Based on the fact that sicknesses are associated with bad spirits connected with some misdeeds to ancestral spirits by the survived members of the community, the need for preventing such instances in life is inevitable. In the like manner, Hay (2012) reveals that animal sacrifices are held by some ethnic minorities to help sick relatives, assure that good spirits watch over their children, and also appease ancestral spirits at healing ceremonies, weddings, house christening and births. Moreover, sacrifices according to Hay (2012) play major roles in appeasing the gods and maintaining relationships with the deity or deities. More so, sacrifices are performed in a nature of rituals as articulated by Hastings (1989) that they explicitly become formal memorials when conducted in the spirit of recalling unforgettable moments in history, a theophany which is the manifestation of deity, the death of a martyr, and the authoritative message of a medium or a prophet. Similarly, Williams (2016) adds that Sacrifices and 
offerings are common acts of worship that may be performed through killing of an animal, which may be given in parts or entirely to ancestors or to God. Hence, offerings and sacrifices are given as gifts to appease God, in order to restore a balanced relationship between God and humanity.

\subsection{Historicity of Ancestors}

As advanced by Cowell (1981) misfortune may perpetuate itself in a given community or individual families coupled with curses if the spirits of the dead are not properly appeased. Curses are still set on people in Africa at all levels of academic or social status based on fears that are perceived to emanate from violating social orders in relation to the dictates of the ancestral spirits. It is stated by Mbiti (1969) that in the spiritual world, the spirits are as quick as the living and that the past does not disappear with death, but lives on through the ghosts of ancestors who mold the fortunes of the earthly.

On the historical basis, Mair (1964) points out that ancestral spirits may be angry because they have not received their due in sacrifices. In order to avert such misfortunes, an object of worship must be put in place which laterally may involve worshippers into veneration of the ancestors. Based on this submission, ancestral veneration could be regarded as an epitome of spiritual implication on Christian experience of God in worship.

\section{RESEARCH METHODS AND MATERIALS}

This study was carried out in the Seventh Day Adventist Church Kenya Lake Conference, covering a section of Luo area in Homa Bay County. The study area has 85 (eighty-five) pastoral districts, 647 (six hundred and forty-seven local churches with a total population of 90,608 (ninety thousand six hundred and eight). This study employed a descriptive research designs with a qualitative research approach which uses a single research paradigm. This was necessary due this single research based on the nature of the study which requires personal interviews with the supposed knowledgeable group of people in order to get the required in-depth information on both social and spiritual life of the targeted population within the area of study. Stratified sampling guided this study by dividing the respondents into categories and randomly selecting subjects relatively based on the population, from where a sample size of 383 respondents was obtained using Dessel (2013) sample size formula, as indicated below.

According to Dessel, (2013), when a researcher has 95\% confidence level and 5\% margin of error, the table below may be useful to guide in determining the sample size as projected against the total population in a given area of study:

For a $95 \%$ confidence level and 5\% margin of error you get following Population $=10,000>$ sample size $=370$ Population $=100,000>$ sample size $=383$

Data was obtained by administering a questionnaire with open-ended questions to a sample of respondents as well as using interviews to probe on detailed information from the members of the SDA church within the Kenya Lake Conference. Finally, data was analyzed using two soft wares MAXQDA and Statistical Package for the Social Sciences (SPSS) Version 23.0 after which it was presented using tables, figures, chats and continuous prose form.

\section{RESULTS AND DISCUSSIONS}

The idea of veneration of ancestral spirits among the Luo community was found to be a reality among as supported with $94.11 \%$ responses from pastors and $86.20 \%$ responses from church elders. The respondents further indicated that one of the most dreaded things among the Luo community is a prolonged illness "Sote" or "Midekre." Both the pastors and the church elders who were interviewed gave their active submission under the following percentages: Pastors, $82.35 \%$ while church elders gave an input of $96.55 \%$ with both accepting that Sote or Midekre could lead the victims and the entire family into the veneration of ancestral spirits. The opinion regarding this condition as accompanying bad spirits and charms, the interviewees explained what it entails by and pointing out that:

Prolonged illness "Sote" or "Midekre" is usually not explainable by the soothsayers, magicians or even the sorcerers. The belief is that an enemy must have secretly planted a forbidden, dangerous tree within the homestead, taken a piece of the sick man's cloth or taken soil from the footprint of the individual to bewitch him/her. By consulting with the witch doctors and soothsayers, the spirits of the dead are equally implored, and possible rituals must take place to appease any of the agonized souls that have come to inflict the survived member of the family with a prolonged illness.

One of the pastors continued to explained that utmost care is directed to a fellow who suffers from such illness "Sote" or "Midekre," and even other general illnesses that may expose one to his or her terminal end to alleviate the rest of their family members any similar situation that may re-occur, inflicted by the spirits of individuals who die without that proper care. That kind of commitment makes it a matter of necessity whatever the faith of that family. To assure the sick of their care upon him or her, the family members will resort to searching all levels of mitigations. These may involve powerful magicians whose magical powers can counteract that of the suspected witch in order to perform charms that may overcome the fascinating powers of the alleged witch. In this manner, the close relative must find a cure for the ill member of the family. Such moments instill fear characterized by a lack of faith in God among Christians to the extent that some of them lose their faith in prayers and the healing power of Christ. In this respect, existential relevance takes charge in place of the mythological might of God.

Hence, superstition takes the tall order culminating into chaos which broadly divides families and communities based on names calling, gossiping, hurling abusive words to each other, and even physical fighting. In some instances, the interviewees pointed out that: "homes are set ablaze and valuable assets destroyed, and in other instances, some suspects have been displaced and forced to live far away from their patrimonial land." In this light, one of the pastors explained an incident stating that:

A renowned church official was implicated with a prolonged illness of his neighbor. After establishing from the witch that his neighbor was responsible for his family problems, he did not engage the church to arbitrate, but instead, marshaled a team of his close family members, who are equally his church 
members to set ablaze the presumed witch's home. The eviction of that family did not leave any peace but instead planted poor relationship between both the church and clan members.

Furthermore, the respondents postulated that: "at such a time like this, the church pastor and elders should come out with wisdom and humility to teach, pray, and arbitrate so that mutual understanding, forgiveness, and restoration are achieved." While doing so, they added that: "the healing power of Christ should conspicuously stand at the horizon of both the antagonizing parties with emphasis that the Great Physician on whom every Christian must rely is Christ Jesus." However, they pointed out that the pastor must remain non-partisan to ensure his ministry is beneficial to the entire community and both the involved families. Moreover, among the respondents, a traumatizing example was brought to light to explain some leaders who preside over Lord's Supper and at the same time, entice their fellow believers who are challenged by prolonged illness to seek attention of witch doctors. The respondents further narrated that:

Some elders, deacons, deaconesses and respected individuals in the church who participate sufficiently in returning tithes and offerings and even take the lead in presiding over Lord's Supper are the ones who direct cases of prolonged illnesses to the witchdoctors. Based on the recognition members have for them in terms of, the success they have in society, and the fact that they affirm that they have succeeded through the same process, lure some church members to follow in their footsteps. The respondents further pointed out that most of our church members believe so much in what the elders of the church say and even what they see in some of the elders' families in terms of prosperous education achievements that their sons and daughters have acquired. With these in mind, they hardly question their counsel in almost every matter.

Swayed by the influence of such notable individuals in the church, some of the challenged individuals through prolonged illness find themselves in the awe of spirits even while pretending to be in church leadership positions. Moreover, some of the respondents who had privy to such visits testified that when they heard the spirits talk and called them by their specific names, they got scared and left without experiencing any haling which was attributed to them as a matter of disbelief. This led to another related aspect of ancestral spirit veneration namely, death and after death rituals also practiced among Luo Seventh-day Adventists in the Kenya Lake Conference.

The results further indicated that a substantial number of SDA Church membership in the Kenya Lake Conference are firmly attached to their Luo cultural beliefs in terms of decision makings and lifestyle. For instance, sickness/prolonged illness, setting up of new homes, the marriage of a son or daughter, wife inheritance, the burial rites, cultural names, burial procedures, death and after death rituals, seeking guidance from magicians, and a misconception regarding the living dead appeared to be some of the outstanding shared principles. All these are attended to not at personal levels but rather at communal basis. These ideas have direct harmony with the opinion advanced by Ogude (2017) in the expression of "umuntu ngumuntu ngabantu," meaning that, a person is a person through persons. The preceding characteristic has a direct link with the mentality of the Luos, for they attach their existence to communal living based on catchwords, "Cham gi wadu," translated as "eat the little you have with your neighbour" This appears to be true Communalism in daily practice among the Luo community as indicated by (Ochieng'-Odhiambo, 2020), that Luos are fond of sharing the little that they have with one another. At the same time, this cultural bond among the Luos in the SDA Church harmonized with the assertion of OchollaAyayo (1980), who postulated that the universality of artistic appeals might take that viewpoint on the way it encompasses various beliefs and practices with peculiar grips on particular groups of people. Hence, Luo cultural traits have profound holds onto each individual member to an extent that any attempt to exonerate a member from it is next to an extinction of life as indicated by Mbiti (1969).

Furthermore, the fact that these cultural bonds are ethnically authentic based on the belief systems expressed through daily practices, the study revealed robust cultural bonds among Luo Christian members of the Seventh-day Adventist church in the Kenya Lake Conference. Hence, active cultural bonds during events such as sickness/prolonged illness, setting up of new homes, the marriage of a son or daughter, wife inheritance, burial procedures, death and after death rituals, seeking guidance from magicians, sorcerers, ancestral spirits and cleansing of the widows were among the reputably entrenched cultural practices among Luo Christian believers in the Seventh-day Adventist Church, Kenya Lake Conference. In these events, members find themselves inclined to fulfilling cultural demands including appeasement rituals to the ancestors. Therefore, the result of the study revealed an outstanding dual allegiance as an implicating factor on Christian worship practices among the Seventh-day Adventists in Kenya Lake Conference.

The presence of this dual allegiance related well with viewpoint of Neyray (2007), who asserted that cultural inclination is appetizing in that human nature for the ancients was, and still is at its best, in a mixture of good and evil. This insinuation was further confirmed on the basis of daily challenges that characterize Christian worship practices of the Luos in the Kenya Lake Conference. The revealed dominance of the cultural traits in the dual allegiance of the Luo cultural life relates well with the claims of Gier (1994), who asserts that at the end of the two contending issues, the dominant culture prevails in the syncretic bargain. This assertion is seemingly true since church members testified that cultural demands are highly esteemed during crisis as compared to the demands of the Scriptures.

Hence, Luos' commitments to their cultural beliefs and their absolute inclinations towards ancestral spirits' veneration appeared to have unquestionable implications on Christian worship practices of the Seventh-day Adventist members in the Kenya Lake Conference. Despite acknowledging the Bible as the spiritual book for nurturing their spiritual life, results indicate that some members hold to traditional ceremonies to accomplish ancestral demands concerning death and after death rituals. The highlighted Luo cultural demands found their parallel with the attempts to make peace with the sick as Lombardo (2018) asserts that the almost dying, would be showered with affection, care and utmost respect. All these are confirmed as positive moves to have the known wrongs settled immediately and ensure that hidden hostilities with the sick and dying individuals are amended with that person in hopes of reconciliation so that the deceased would not return to haunt their supposed wrongdoers. On the other hand, Luo cultural ceremonial obligations in terms of wife inheritance, 
Tero Buru, cleansing and sexual responsibilities for both the living and dead widows must be on the historical basis as Mair (1964) points out that ancestral spirits may be angry and in turn torment the living for not dealing with them fairly in offering them their dues. To avert such imminent misfortunes, an object of worship is put in place which, horizontally, may involve worshippers into veneration of the ancestral spirits.

Although numerous participants acknowledged that marriage is an institution set by God, the results revealed that some of the SDA church members in the Kenya Lake Conference still hold that marriage encompasses sacred aspects. Some of these products shown in the results included the seasons of planting and harvesting, conflict resolutions, cementing agreements, getting children and also to have a formal union. Because of the understanding that most of the SDA Church members tend to memorize cultural beliefs more, compared to the Christian principles outlined in the Bible, the results indicated that there was a significant challenge of these members having full trust in God. The same idea attributed to the understanding that Luo cultural lifecycle is saturated by the daily cultural stimulants in almost every SDA Church member in the Kenya Lake Conference.

It also came out that some of the fundamental aspects found to be infiltrating daily Luo cultural practices are found in the children's naming. In this light, a name given to children among the Luo community entails time and incidences in life as in the African context. For instance, Odhiambo is the name given to the boy child born in the evening. On the other hand, a girl child born in the evening is named Adhiambo while Achieng' will be the name given to a female child born during midday. Therefore, naming is a robust cultural practice that may not conflict with Christian ways if taken positively. However, in the Luo cultural domain, child naming carries various phenomena. In a situation where a child cries hysterically, names of ancestors are called with the belief that some of the ancestors are struggling to be incarnated through the naming of the young child. The result revealed that the crying child would stop crying at the mention of a given ancestor's name. Such a notion maintains that the incarnated ancestor will infuse some of his or her character traits in the child named after them.

Even though most participants indicated that the dead knows nothing, the connection between the living and dead, exposed different revelations. Most of the participants noted that the dead represents a bad omen to the living. Others argue that the dead watch over the residence, while other members hold that the dead influence the living in various aspects in life including marital status. These notions are vital in understanding the predominant influence of cultural believes in believers. The results revealed that cultural influences penetrates human existence naturally to an extent that they are not felt like any violation of Christian standards. This submission agrees with the idea advanced by Cotton (1993) who postulated that culture permeates the existence of many people and it contiguously contracted like a common cold whose manifestation twice in a year is a usual norm. However, Cotton (1993) pointed out that even though it is not natural to have the sneezing, wheezing, coughing, and congestion, sore throat, fever and headache are associated with the disease. Typically, the results indicated witchcraft, in this case, was associated with evil spirits, and bad omen. Nevertheless, witchcraft, act of sorcerers and divination which are predominantly manifested as modes of resolving some difficulties, includes lack of jobs. Therefore, most members could seek guidance from witch doctors when confronted with challenge, especially when death occurs in their family members. The reasons for consulting ancestors for bright future and conflict resolutions gave clear indicators that they believed that the dead were still alive, and affect the daily operations of the members.

This same issue is especially understood in the submission of German (2005), who stated that nothing happens by chance; and for this reason, it is crucial to seek guidance from a specialist to ascertain the cause of misfortune, determine the right course of action, seek paths to avoid danger and to chart ways into the future. Furthermore, the observed lack of strong faith in God as a sole provider whose words carry active creative power, as indicated in the book, Christian Believes (2015), often led members to seek guidance from the ancestors. In line with these perceptions and the understanding, the results displayed that the most outstanding belief was that misfortunes befall people because of infuriated ancestors, unresolved fears of bad omens, and witchcraft, as indicated in the table below. 

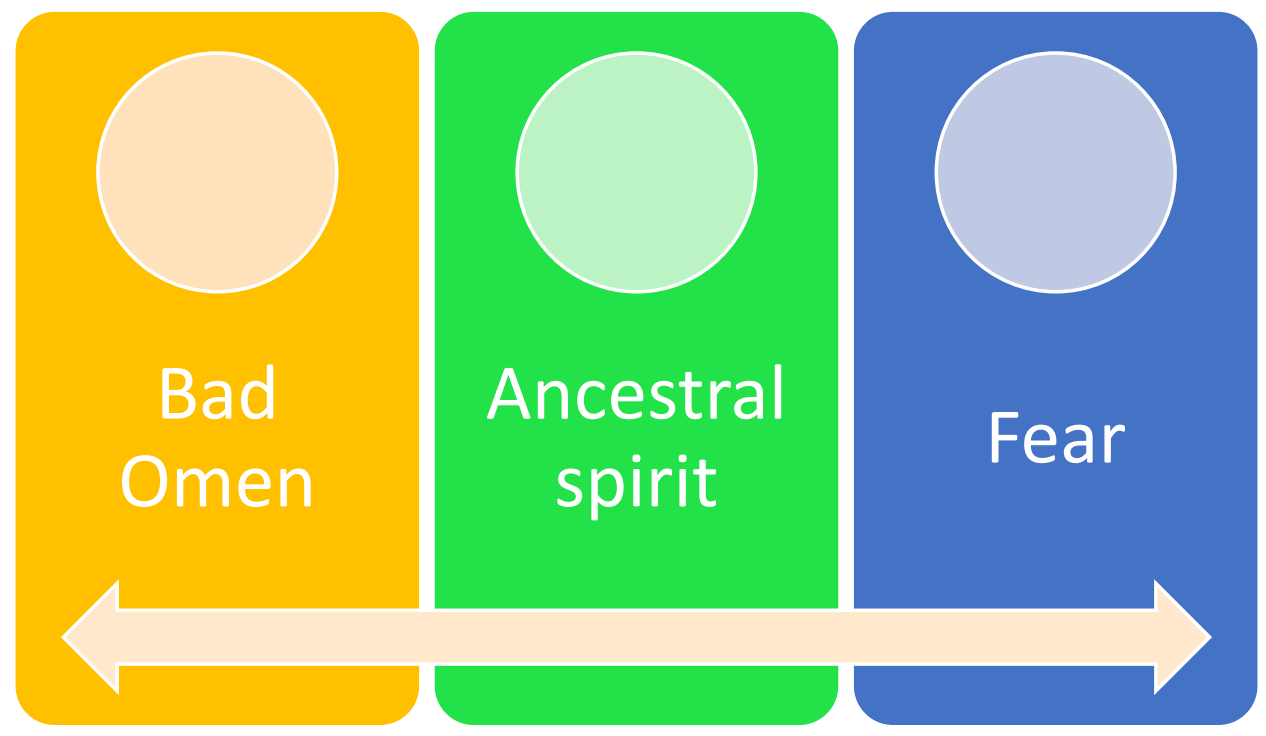

Source: Field data (2020)

The study indicated that among Seventh-day Adventist Church members in the Kenya Lake Conference there is believe in ancestral spirits, which are associated with fear and bad omen. Furthermore, these dreaded traits would take effect if the Luo Christian believers would flout cultural dictates. Some of these cultural dictates included but not limited to: (i) proper direction of the head of the man and the woman of the home during his or her burial, (ii) fulfillment of the death and after death rituals (iii) sexual obligations at their prescribed time for the living and the living dead (iv) child naming (v) aversion of the evil spirits. The study further established that there was a misconception about the conscious state of the dead. At the same time, SDA church members confirmed during their submissions that the dead practically influence the lives of their living relatives either positively or negatively, an understanding that paints contradictions regarding the revelation of the Bible about the deceased. In response to such influences, most members continue to embrace Luo cultural practices and rituals to appease ancestral spirits.

The perceived advantage based on existential relevance for straight forwarded answers from the ancestors than one would expect it from God; attract the attention of the church members.
This notion compares well with the assertions of Hierbert (1999), who stated that the ancestors have the wellbeing of families at heart, and being that they are the founders of families, they have a natural interest in caring for it. Based on these necessitating lucrative elements in the Luo beliefs in ancestral spirits' awe, the pastors serving in the Kenya Lake Conference face numerous challenges about their gospel work at their respective churches.

The study also indicated that some of the notable challenges were pertaining to members' involvements in matters including but not limited to witchcraft, magicians, ancestral spirits, and cases of prolonged illness ("Sote"or Midekre). The reason for the perpetual quest for ancestral intervention was entirely because some notable members of the church including church leaders visited witch doctors, magicians, and appealed to the involvement of the ancestral spirits to sort out matters of infertility, prolonged illness (Sote or Midekre). The result also established that the same leaders championed members who had similar problems to follow in their examples for help. It was in this light that the chart indicated below explains the percentage disparities as a summary of the entire episode. 


\section{Attention given to ancestral spirits}

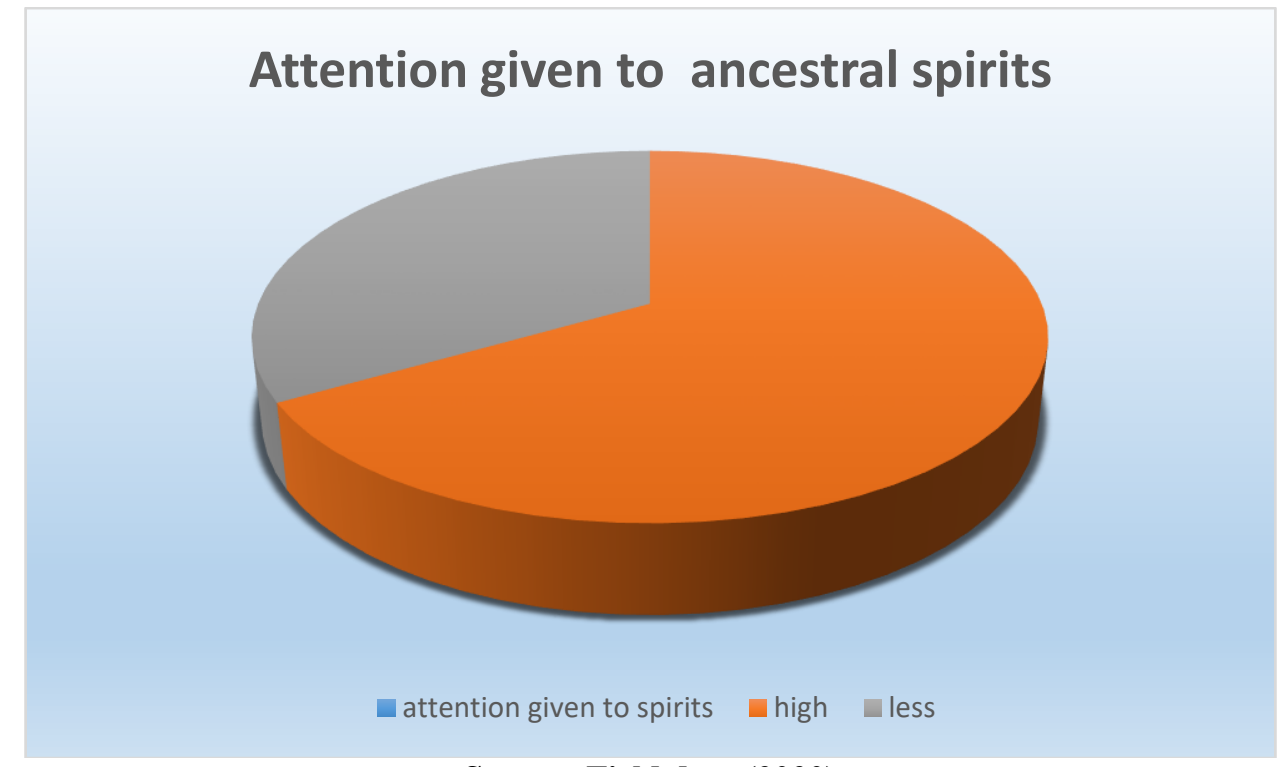

Source: Field data (2020)

Hence, this pie chart sums up the results gleaned from the data, which revealed that more significant percentage of the Seventh-day Adventist Church members in the Kenya Lake Conference were giving more attention to ancestral spirits. The rationale behind this high percentage is pegged in the major factors, including but not limited to existential relevance, the historicity of ancestors, anticipated gains, the cultural predispositions and solidarity of the community. Therefore, the study exposed the act of dual allegiance among Seventh-day Adventists' in the Kenya Lake Conference. This resonates with the claim by Rushdoony (2008) that any moral compromiser intentionally sets back from a godly stand because he prefers another opinion. Hence, he chooses another viewpoint because his real faith lies somewhere else. In this sense, the study found out most of the SDA Church members in the Kenya Lake Conference do not have confidence in matters of faith absolutely, but rather blend various traditional elements with Christian expressions. From this understanding, the study explored the Seventh-day Adventist church practices about the God's worship in the Kenya Lake Conference.

Consulting ancestral spirits is predominant among the SDA Church members in Kenya Lake Conference. The Luo culture is centered on the socio-cultural landscape where the members subscribe to their ethnicity through burial, building a house, setting up a home, and performing rituals. The Luo community usually redefines their history through rehearsal in which the modern themes get reworked by the respective elders. These elders write, customize the past, and validate their authority as the Luo clan's primary custodians whose ideas must be trusted and complied with. For this reason, most of the SDA Church members in Kenya Lake Conference would subscribe more to the traditional elders and the ancestral spirits than they are expected to live with SDA Church worship practices. This notion was found to be deeply rooted among the Luos since they perceive their elders as divine leaders that guide the community on the political, economic, and social perspectives as indicated by (Owuor, 2006). The same idea was confirmed from a widespread exclamation that whatever Raila "Agwambo" has said must be treated with finality and "No Raila No peace" slogan has been perpetually heard all over confirming the trust Luo community and even others have in this historical Luo leader (Smedt 2009). Such kind of enthusiasm behind a fledged Luo elder was seen as coming with a natural force that may not be withheld by any contending forces.

\section{CONCLUSION}

In making the conclusion of the study, the aforementioned functional theory of religion was confirmed in the assertion of Durkheim (1912), who emphasized that religion is all about community since it binds and provides people with social cohesion, promotes behavior consistency in terms of voluntary social control, and offers meaning, purpose and strength during life's changeovers and tragedies such as illnesses, death and other associated catastrophic events affecting humanity. This submission was confirmed on the basis that religious activities are culturally universal and have the potential to fulfill several functions within human societies. Furthermore, the essentiality of religion was considered as inevitable as was pointed out by Tylor (1917) that beliefs in spiritual beings was and is still the essential source for all religions. Based on the fact that religion may function on several ritualistic domains, there are certain essential elements relating to supernatural powers that may not be dispensed with; such as the nature of God and His divine will as revealed in the Bible. Hence, Luo cultural beliefs in ancestral spirits and SDA Church worship practices appeared as religious practices that may not be dispensed with.

\section{REFERENCES}

[1] ANCESTOR WORSHIP (CHINESE: 神, PINYIN: FÙ), VENERATION AND OFFERING IN TAOISM (2016) https://www.nationsonline.org/oneworld/Chines

[2] Barkan, S.E., and Greenwood, S. (2003). Religious Attendance and Subjective Well-Being among Older Americans: Evidence from the General Social Survey, Review of Religious Research 45:116-129.

[3] Bondi V. (June 15, 2015). Death and burial in the African Context

[4] Brown, J. P. (1998). Understanding and applying medical anthropology. London, Mayfield Publishing Company 
[5] Brown, S.R. (2010). Africa's Roots in God (New York: Hempstead,) of Cross-Cultural Research.

[6] Cowell, A. (1981). In parts of Africa, Ancestral spirits guide the Living, Special to the New York Times

[7] Dessel, G.V. (2013), How to determine population and survey sample size? https://www.checkmarket.com/blog/how-to-estimate-your-population-andsurvey-sample-size/

[8] Evans-Pritchard, E.E., R. (1934). Firth, B. Malinowski \& I.Schapera (eds) Essays presented to C.G. Seligman. London: Kegan Paul.

[9] Gehman, R. J. (2005). African Traditional Religion in Biblical Perspective. East African Educational Publishers, Nairobi, Kampala and Dar es Salam.

[10] Hastings, A. (1989). African Catholicism. Essays in Discovery, Trinity International, London

[11] Hays J. (2012). Religion in the Developing World (third world), New York Times, Washington Post, Los Angeles Times, Times of London,

[12] Hiebert, P. (2000). Spiritual Warfare and Worldview, Nairobi Kenya

[13] HISTORY OF CHINA- ANCESTOR WORSHIP, VENERATION AND OFFERING IN TAOISM (2017)

[14] Maina, S.M. (2012). Qualitative and Quantitative Research Methods Simplified. Nairobi: mwituria publishers; UoN Websites Search. Enter your keywords:

[15] Mair, L.P. (1964). Witchcraft as a Problem in the Study of Religion. London School of Economics

[16] Magher, M. (2018). What Is the Meaning of Conceptual Framework inResearch?

[17] Martin R.P. (1976). Worship in the Early Church, William B. Errdmans Publishing Company, Grand Rapids.

[18] Mbiti J.S. (1969). African Religion and Philosophy, East African Educational Publishers: NRB, Kenya.

[19] Merwe P. J. (2008). Ancestor worship - is it Biblical? Department of Science of Religion and missiology Missiology. University of Pretoria

[20] Mndende N. (2005). Ancestors, Spirits and Healing in Africa and Asia: A Challenge to the Church: Ancestors and Healing in African Religion: A South African Context, Lutheran World Federation, Switzerland.

[21] Mugenda, O. M. \& Mugenda, A. G. (2003). Research methods: Quantitative and qualitative Approaches. Nairobi: African Centre for Technology Studies.

[22] Ntozi J. P. (1997). Widowhood, remarriage and migration during the HIV/AIDS epidemic in Uganda. Health Transit Rev. (Supple):125-44.
[23] Nurnberger, K. (2014). The living dead and the living God, Christ and the ancestors in a changing Africa, Cluster Publications, Pietermaritzburg.

[24] Okpechi, A. (2018). The 14 Traditional Burial Rites of the Luo People of Kenyahttps://allafrica.com/stories/201810100020.htm

[25] Omondi F.A. (2017). Influence of Luo Traditional Religion on African Israel Nineveh Church in Alego Usonga Constituency, Kenya * Department of Religion, Philosophy and History Jaramogi Oginga Odinga University of Science and Technology

[26] Owuor, V. B. (2006). Resurrection hope in the African context: Challenging Luo beliefs and practices concerning death (Doctoral dissertation, NorthWest University).

[27] Powell, K. (2019). The History of Death and Burial Customs,Kimberly Powell, Professional genealogist, author and educator, is the author of The Everything Guide to Online Genealogy

[28] Richards C. (2016). What are the Six Basic Human Needs?

[29] SAHO, (2019). https://www.sahistory.org.za/article/african-traditionalreligion

[30] SHIINO, W. (1997). Death and Rituals among the Luo in South Nyanza Tokyo Metropolitan University

[31] Smedt, J. De (2009).'No Raila, No Peace!' Big man politics and election violence at the Kibera grassroots African Affairs, academic.oup.com

[32] Tylor, B. (1917). The Essentials of Religion https://science.jrank.org/pages/11031/Religion-Essentials-Religion.html

[33] Wigington, P. (2019). Ancestor Worship in Pagan Cultures, Patti Wigington is a pagan author, educator, and licensed Clergy.

\section{AUTHORS}

First Author - Ogayo Luka Otieno, PhD Student, Department of Philosophy and Religious Studies, Kisii University, Email -

lukeogayo@gmail.com

Second Author - Dr. Richard Ayako (DMin), Lecturer, School of Arts and Social Sciences, Kisii University, Email ayako@kisiiuniversity.ac.ke

Third Author - Dr. Daniel Rotich Kandagor, PhD, Lecturer, School of Arts and Social Sciences, Kisii University

Email-dkandagor@kisiiuniversity.ac.ke 